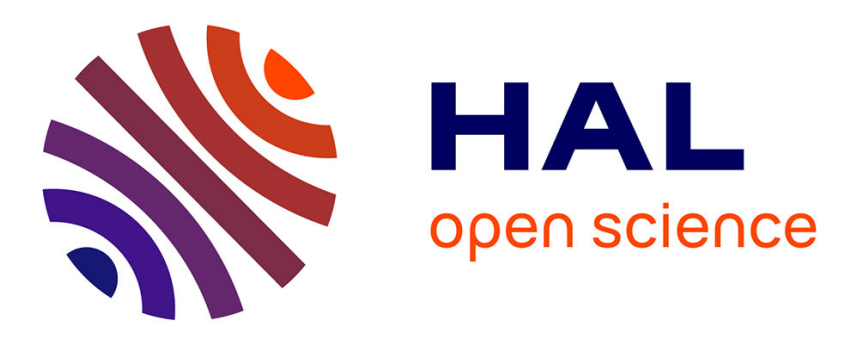

\title{
Evaluation of Cell Membrane Effects After 3D Multicellular Spheroids RF Exposure
}

Jelena Kolosnjaj-Tabi, Geraldine Alberola, Sylvain Augé, Amar Tamra, David Dubuc, Katia Grenier, Marie-Pierre Rols

\section{- To cite this version:}

Jelena Kolosnjaj-Tabi, Geraldine Alberola, Sylvain Augé, Amar Tamra, David Dubuc, et al.. Evaluation of Cell Membrane Effects After 3D Multicellular Spheroids RF Exposure. 2020 IEEE MTTS International Microwave Biomedical Conference (IMBioC), Dec 2020, Toulouse (virtuel), France. pp.1-3, 10.1109/IMBIoC47321.2020.9385011 . hal-03253240

\section{HAL Id: hal-03253240 \\ https://hal.laas.fr/hal-03253240}

Submitted on 8 Jun 2021

HAL is a multi-disciplinary open access archive for the deposit and dissemination of scientific research documents, whether they are published or not. The documents may come from teaching and research institutions in France or abroad, or from public or private research centers.
L'archive ouverte pluridisciplinaire HAL, est destinée au dépôt et à la diffusion de documents scientifiques de niveau recherche, publiés ou non, émanant des établissements d'enseignement et de recherche français ou étrangers, des laboratoires publics ou privés. 


\section{Evaluation of Cell Membrane Effects after 3D Multicellular Spheroids RF Exposure}

\author{
Jelena Kolosnjaj-Tabi \\ Cellular biophysics \\ Institute of pharmacology and \\ structural biology \\ Toulouse, France \\ jelena.kolosnjaj-tabi@ipbs.fr
}

\author{
Geraldine Alberola \\ Cellular biophysics \\ Institute of pharmacology and \\ structural biology \\ Toulouse, France \\ geraldine.alberola@ipbs.fr
}

\author{
Katia Grenier \\ $L A A S-C N R S$ \\ Université de Toulouse, CNRS, \\ UPS \\ Toulouse, France \\ grenier@laas.fr
}

\author{
Sylvain Augé \\ LAAS-CNRS \\ Université de Toulouse, CNRS, \\ UPS \\ Toulouse, France \\ sylvainauge@hotmail.fr
}

\author{
Amar Tamra \\ $L A A S-C N R S$ \\ Université de Toulouse, CNRS, \\ $U P S$ \\ Toulouse, France \\ amar.tamra@hotmail.com
}

\begin{abstract}
Herein we present the assessment of RF-induced cell membrane effects assessment in multicellular spheroids, which are three-dimensional tissue models resembling small avascular tumors. The RF exposure was performed in a dedicated RF applicator, which allowed a precise RF metrology as well as calibrated and systematized conditions of application of electromagnetic fields to multiple 3D multicellular spheroids. The used RF micro-device allowed us varying different RF parameters (such as frequency, power, or modulation) in order to evaluate RFrelated biological effects on the membranes of cells constituting the multicellular spheroids. The effects of electromagnetic signals were assessed on cancer cells spheroids made with HCT-116 cells. Appraised parameters included the evaluation of cell membrane integrity, and the assessment of spheroids global structure after illumination. After RF exposure at Specific Absorption Rate values ranging from 0.4 to $37 \mathrm{~kW} / \mathrm{kg}$ (attaining a thermal increment $\Delta \mathrm{T}_{\max }$ up to $6^{\circ} \mathrm{C}$ ), we did not observe any detrimental effects on the membrane level. Moreover, the spheroids exhibited an unmodified architecture.
\end{abstract}

Keywords - microwave, micro-technologies, $R F$ effects, biological effects, cell membrane, cell organelles, micronucleus, 3D cellular models

\section{INTRODUCTION}

The biological effects that might be induced by radiofrequency $(\mathrm{RF})$ radiation attract considerable scientific and public attention. The main open questions are whether or not RF radiation can be harmful and what the RF-exposure thresholds are. In order to answer these questions, it is necessary to design exposure systems, allowing calibrated and systematized

This work was partly supported by the French national project grant $\mathrm{n}^{\circ}$ ANR-15-ASTR-0017 and by LAAS-CNRS micro and nanotechnologies platform of the French RENATECH network. conditions of application of electromagnetic fields. In this context, we developed a calibrated RF micro-device working in a near field configuration and tested it using different RF parameters (such as frequency, power, or modulation), in order to evaluate RF-related biological effects. Unlike classical devices, where living cells are illuminated in 2D cultures, mainly with far field test setups [1]-[5], we herein present the use of a RF applicator, which allows RF-exposure of 3D multicellular spheroids.

This 3D model provides many assets: it combines the advantages of both 2D cells culture model and in vivo testing with an easy access to various cell lines, a rapid growth, at a limited and affordable cost, as well as a more important complexity, which is more relevant of the living, while avoiding in vivo testing. Cancer cells multicellular spheroids thus represent a 3D micro-tissue model, which resemble small avascular tumors. Moreover, spheroids may also be compatible with miniature RF exposure systems using micro-technologies.

The device which was used in this study allows a simultaneous illumination of five multicellular spheroids. The exposure system thus allows a high throughput analysis of potential biological effects, induced by RF electromagnetic signals, resembling to the ones used in Bluetooth or wireless technology.

\section{ARCHITECTURE OF THE RF APPLICATOR NETWORK AND ASSOCIATED TECHNOLOGY}

A miniature RF applicator suitable for illuminating microtissues was developed. The device consists of a coplanar waveguide ended by a capacitive patch. The latter is crossed by a microfluidic channel, which includes a specific area dedicated to the micro-tissue localization. This channel is associated to two 
reservoirs placed apart, maintaining the micro-tissue within its culture medium during RF exposures duration. This structure is fully electromagnetically characterized. Its experimental dosimetry study may be found in [6] as well as the exposure test bench.

In order to allow a sufficient statistical evaluation of electromagnetic fields impact on cells and due to its miniature size, the structure was adapted to enable the simultaneous RF illumination of five micro-tissues. This network configuration is shown in Fig. 1. Micro-tissues are located within each fluidic reservoir, which are drawn in pink color on the schematic, at the end of small length coplanar lines. A main coplanar waveguide (drawn in blue color) is used to feed the five RF applicators. Due to the coplanar configuration of the waveguides, metallic bridges for ground balancing are required at the input of each RF applicator. Fig. 2 presents a zoomed view of one RF applicator, which integrates the micro-tissue area above the capacitive patch.

To realize such a structure, the technological process is performed in 4 main steps. The coplanar lines are first fabricated with a lift-off process and using a thin seed layer of titanium followed by a $0.3 \mu \mathrm{m}$ thick gold layer. A bio-compatible polymer layer is then patterned to isolate the micro-tissue from the metallic layer. An additional metallic layer is subsequently patterned on top to avoid any ground unbalance at the intersection of the RF applicator feed lines and the main coplanar waveguide. Finally, the high fluidic walls are fabricated with a $500 \mu \mathrm{m}$ thick polymer layer to realize the fluidic reservoir and channels.
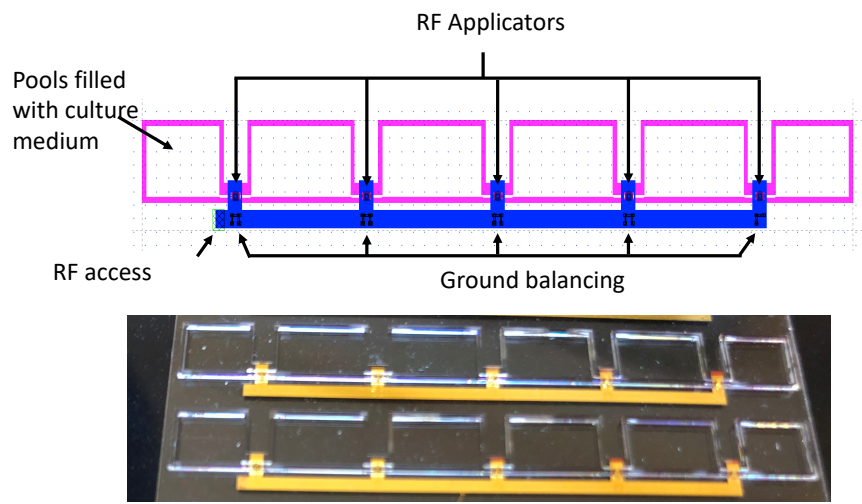

Fig. 1. Schematic and photography of the RF applicators network associated to culture medium pools.

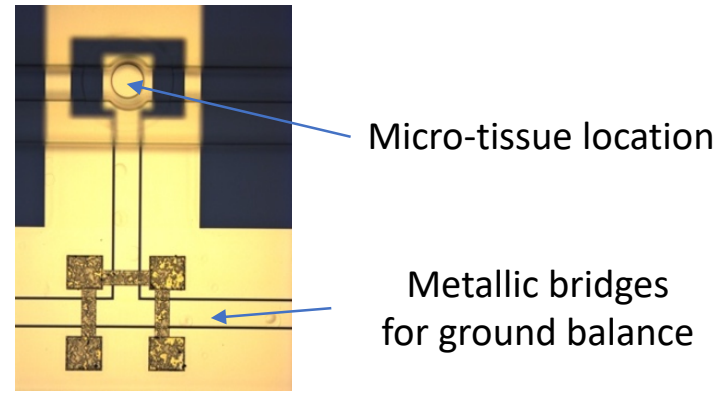

Fig. 2. Zoomed view of a RF applicator for micro-tissue with metallic bridges used for ground balancing along the principal coplanar waveguide.
The RF exposure setup, composed of an RF source is then connected to the coplanar structure using a cable and a coplanar probe.

Such a structure, implying non-sub-wavelength transmission lines connected to sensing capacitors, presents stationary waves at $2.45 \mathrm{GHz}$. This translates into different maximum electrical fields developed in each capacitor and consequently different Specific Absorption Rate - SAR - values for each micro-tissue location.

\section{Biological EFFECts AFter Multicellular SPHEROIDS RF EXPOSURE : FOCUS ON CELL MEMBRANE INTEGRITY}

Multicellular spheroids were exposed to RF signals in continuous waves $(\mathrm{CW})$ at $2.45 \mathrm{GHz}$. The exposure lasted 5 minutes, after which we examined the cell membrane integrity of cells constituting multicellular spheroids. This procedure involved the use of propidium iodide (PI), a small molecular probe, which has an increased fluorescence yield after penetration into the cell. The PI penetration can occur when the cell membrane is damaged, such as in cases when spheroids are exposed to short and intense electric field pluses, which were applied to the positive control as previously described [7].

Different conditions were applied to spheroids in order to ensure the results. Positive controls consisted in spheroids treated with pulsed electric field (eight pulses lasting $100 \mu \mathrm{s}$, which were delivered with stainless steel parallel plate electrodes, at a frequency of $1 \mathrm{~Hz}$ and field intensity of 1.3 $\mathrm{kV} / \mathrm{cm}$ ), and thus presented membrane defects. Negative control were untreated spheroids, whereas sham were spheroids that were placed in the device but were not illuminated. Finally, RFexposed spheroids were illuminated within the RF micro-device.

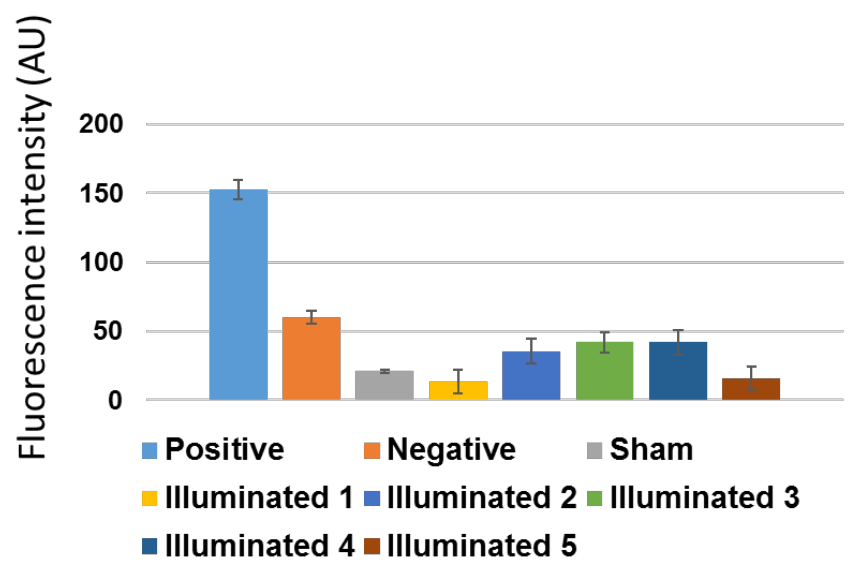

Fig. 3. Fluorescence intensity quantification after propidium iodide (PI) intake following five minutes RF-exposure (in CW mode) of HCT-116 multicellular spheroids.

The numbers 1 to 5 denote the position within the applicator, with position No 4 correlating with the lowest SAR $(0.43 \mathrm{~kW} / \mathrm{kg}$ for a source power of $33 \mathrm{dBm}$ ) and position No 2 correlating with the highest SAR $(7.5 \mathrm{~kW} / \mathrm{kg}$ for a source power of 33 $\mathrm{dBm})$. The graph shows the mean values and corresponding standard deviations, while $\mathrm{N}_{\text {positive }}=3, \mathrm{~N}_{\text {negative }}=5, \mathrm{~N}_{\text {sham }}=4$, $\mathrm{N}_{\text {illuminated }}=5$ per position within the micro-device.Fig. 3 
presents the fluorescence intensity quantification after propidium iodide (PI) intake following five minutes RFexposure (in CW mode) of HCT-116 multicellular spheroids as well as for the different control configurations. Under our experimental conditions, RF signals did not alter the integrity of cell membranes (Figure 3), which resulted in lower fluorescence intensity of illuminated spheroids in comparison to the positive control.

Representative cancer cells spheroids fluorescence is shown in Fig. 4, where A) corresponds to the positive control treated with pulsed electric field (eight pulses lasting $100 \mu$ s, which were delivered with stainless steel parallel plate electrodes, at a frequency of $1 \mathrm{~Hz}$ and field intensity of $1.3 \mathrm{kV} / \mathrm{cm}$ ), B) is a sham placed in the device but not illuminated, and C) is a spheroid illuminated at the highest SAR $(7.5 \mathrm{~kW} / \mathrm{kg}$ for a source power of $33 \mathrm{dBm}$ ).

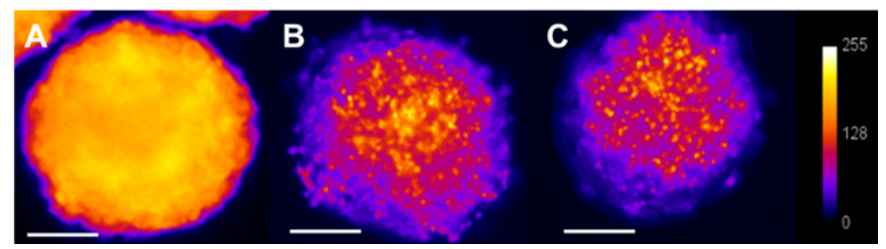

Fig. 4. Fluorescence micrographs of representative multicellular spheroids. The fluorescence is represented in a pseudo-color scale (fire scale obtained by the ImageJ software). Scale bar: $100 \mu \mathrm{m}$.

After RF exposure, the multicellular spheroids remained spherical (Fig. 4). The cells forming the spheroids did not detach, and we did not observe any membrane blebs on the outer rim of the micro tissue.

\section{CONCLUSIONS}

In the present work, we present the assessment of the impact of RF signals exposure on cell membrane integrity. This is enabled with the combination of both a multi-spheroid RF applicator specifically developed and a strict biological protocol applied to several illuminated micro-tissues and controls. Under exposure conditions described herein, we did not observe any alterations in cell membrane permeability. Moreover, RF exposure did not alter spheroids architecture. Additional tests will be performed to assess any potential damage on cell organelles.

\section{REFERENCES}

[1] T. Wu, T.S. Rappaport, C.M. Collins, "Safe for generations to come," IEEE Microwave Magazine, pp. 65-84, March 2015.

[2] A. Paffi et al., "Considerations for Developing an RF Exposure System: A Review for in vitro Biological Experiments," IEEE T-MTT, vol. 58, $\mathrm{n}^{\circ} 12$, pp. 2702-2714, 2010

[3] M. Zhadobov et al., "Exposure System and Dosimetry for In Vitro Studies of Biocompatibility of Pulse-Modulated RF Signals of Ultrahigh Field MRI," IEEE Trans. On Biomed. Eng., vol. 60, n 11, pp. 3167-3175, Nov. 2013.

[4] A. Perrin et al., "Evaluation of the co-genotoxic effects of $1800 \mathrm{MHz}$ GSM radiofrequency exposure and a chemical mutagen in cultured human cells," C. R. Physique, vol. 11, pp. 613-621, 2010.

[5] J. Schuderer et al., "In vitro exposure systems for RF exposures at 900 MHz," IEEE T-MTT, vol. 52, n8, pp. 2067-2075, Aug. 2004.

[6] A. Tamra, et al., "Experimental Dosimetry Study of a Miniature RF Applicator Dedicated to the Evaluation of Severe RF Exposure Impact on a 3D Biological Model," Proceedings of the IEEE International Microwave Symposium, June 2020. 